\title{
Efficiency of early selection for rotation-aged wood quality traits in radiata pine
}

\author{
Harry X. WU ${ }^{a *}$, Mike B. PowelL ${ }^{\mathrm{c}}$, Junli L. YANG ${ }^{\mathrm{b}}$, Milo IVKovića ${ }^{\mathrm{a}}$, Tony A. McRAE \\ ${ }^{\text {a }}$ Ensis, CSIRO, PO Box E4008, Kingston, ACT 2604, Australia \\ ${ }^{\mathrm{b}}$ Ensis, CSIRO, Private Bag 10, Clayton South VIC 3169, Australia \\ c Southern Tree Breeding Association Inc, PO Box 1811, Mount Gambier SA 5290, Australia
}

(Received 6 December 2005; accepted 19 June 2006)

\begin{abstract}
A total of 360 bark-to-bark-through-pith wood strips were sampled at breast height from 180 trees in 30 open-pollinated families from two rotation-aged genetic trials to study inheritance, age-age genetic correlation, and early selection efficiency for wood quality traits in radiata pine. Wood strips were evaluated by SilviScan ${ }^{\circledR}$ and annual pattern and genetic parameters for growth, wood density, microfibril angle (MFA), and stiffness (modulus of elasticity: MOE) for early to rotation ages were estimated. Annual ring growth was the largest between ages $2-5$ years from pith, and decreased linearly to ages 9-10. Annual growth was similar and consistent at later ages. Wood density was the lowest near the pith, increased steadily to age 11-15 years, then was relatively stable after these ages. MFA was highest $\left(35^{\circ}\right)$ near the pith and reduced to about $10^{\circ}$ at age $10-15$ years. MFA was almost unchanged at later ages. MOE increased from about $2.5 \mathrm{GPa}$ near the pith to about $20 \mathrm{GPa}$ at ages 11-15 years. MOE was relatively unchanged at later ages. Wood density and MOE were inversely related to MFA. Heritability increased from zero near the pith and stabilised at ages 4 or 5 for all four growth and wood quality traits (DBH, density, MFA and MOE). Across age classes, heritability was the highest for area-weighted density and MFA, lowest for DBH, and intermediate for MOE. Age-age genetic correlations were high for the four traits studied. The genetic correlation reached 0.8 after age 7 for most traits. Early selection for density, MFA and MOE were very effective. Selection at age 7-8 has similar effectiveness as selection conducted at rotation age for MFA and MOE and at least $80 \%$ effective for wood density.
\end{abstract}

early selection / microfibril angle / modulus of elasticity / wood density / radiata pine

Résumé - Efficacité d'une sélection précoce pour les propriétés du bois adulte chez le pin radiata. Cette étude a pour objectif d'estimer les paramètres génétiques (héritabilités et corrélations juvéniles-adultes) pour différentes propriétés du bois chez le pin radiata et d'évaluer l'efficacité d'une sélection précoce. Trois cent soixante échantillons diamétraux de bois ont été prélevés dans deux dispositifs génétiques adultes sur trente familles de pin radiata issues de pollinisation libre, puis analysés avec le SilviScan ${ }^{\circledR}$. Les caractéristiques annuelles de la croissance, de la densité du bois, de l'angle des microfibrilles (MFA) et de la rigidité (module d'élasticité : MOE) ont été analysées et les paramètres génétiques de ces caractères ont été estimés du stade juvénile à l'âge de la révolution. La croissance radiale est la plus forte entre 2 et 5 ans (depuis la moelle) puis décroît linéairement jusqu'à neuf-dix ans et se stabilise ensuite. La densité du bois est la plus faible près de la moelle; elle augmente fortement jusqu'à 11-15 ans puis se stabilise. MFA est le plus élevé $\left(35^{\circ}\right)$ près de la moelle; il diminue ensuite pour atteindre environ $10^{\circ}$ vers $10-15$ ans. MFA ne varie pratiquement plus au-delà de cet âge. MOE passe de $2.5 \mathrm{GPa}$ près de la moelle à environ $20 \mathrm{GPa}$ à $11-15$ ans. Il se stabilise ensuite. L'évolution de la densité du bois et de MOE au cours du temps est donc inverse de celle de MFA. L'héritabilité, égale à 0 près du cœur, augmente ensuite et se stabilise vers 4-5 ans pour tous les caractères de croissance et les propriétés du bois (diamètre, densité, MFA, MOE). Quel que soit l'âge, l'héritabilité est la plus élevée pour la densité et MFA, la plus faible pour le diamètre et intermédiaire pour MOE. Les corrélations âge-âge sont fortes pour tous les caractères étudiés. Les corrélations génétiques atteignent 0.8 après 7 ans pour la plupart des caractères. Une sélection précoce pour la densité, MFA et MOE apparaît très efficace : en effet, une sélection vers 7-8 ans a la même efficacité qu'une sélection réalisée à la révolution pour MFA et MOE et cette efficacité est d'au moins $80 \%$ pour la densité du bois.

sélection précoce / angle des microfibrilles / module d'élasticité / densité du bois / pin radiata

\section{INTRODUCTION}

Considerable research has been conducted on age-age genetic correlation and efficiency of early indirect selection in conifers. Most studies were focused on age-age correlation of the same trees for growth traits with the aim to determine the optimal age and traits for backward or forward selection $[27,48]$. When examined on a short period, say before age 15, age-age correlations were generally high [50]. However, estimates varied widely when examined at more than half the rotation age. They ranged from low or moderate in Pinus elliottii [21], Picea glauca [30], Pinus pinaster [10], and Pinus taeda [19] to high in Pinus radiata [6], Pseudotsuga menziesii [2,23], and several other Pinaceae (or Pinus) species [26]. The varying results were probably related to species and sample size differences, diverse test environments and designs, and silvicultural treatments, among other factors.

\footnotetext{
* Corresponding author: Harry.wu@ensisjv.com
} 
Research in early selection was also conducted on retrospective studies where the performance of young seedlings in controlled environments was related to the late performance of their siblings in plantations. Retrospective studies are replications of family performance in space and time, often designed to uncover early indicator traits $[37,46]$ and optimal early testenvironments $[28,51]$ that would maximise the early-late age genetic correlations. In studies where environmental factors, limiting in the field, have been mimicked, the early-late genetic correlations were improved [17]. Other studies have suggested that ontogenetic development of the seedlings were crucial [44].

Age-age genetic correlation and early selection studies have been extended to wood quality traits in recent years [20]. In Scots pine (Pinus sylvestris), it was observed that early selection for tracheid length and wood density would be most effective at age 11 for age 33 years trees. Genetic correlation between early ages and age 12 years were very high and the correlation reached 1 at age 5 years for density including earlywood and latewood density [22]. Early selection for radiata pine (Pinus radiata) has been examined in growth and wood density. Cotterill and Dean [6] observed early selection at age 6.5 was effective for diameter and basal area at age 16 in Australia. King and Burdon [24] studied the time trend in inheritance and projected efficiencies of early selection in a large 17 -year-old progeny test in New Zealand and indicated that maximal gain per annum, with selection at age 7-8 years for rotations of 25-30 year was achievable for stem volume. From a small set of diallels, Matheson et al. [32] observed that selection at age ten had the greatest gain per year for age 14 crosssectional area and Nyakuengama et al. [35] observed that selection for pulpwood quality traits (fiber perimeter, coarseness, specific surface, and ring density) would be effective at age 8 9 years for the first 15 rings. Recently, Kumar and Lee [25] reported that early selection of wood density at core age 5 years would be effective for family and individuals for age 30 year trees in New Zealand.

Radiata pine, the most important plantation species in Australia, has about 750000 ha of plantations [47]. Of the 7.3 million cubic meters of softwood sawlogs and veneer logs, valued at $\$ 460$ millions at the mill gate annually [1], radiata pine logs currently contribute more than $70 \%$. Radiata pine is indigenous to California and two islands off the coast of Mexico. It is the most extensively planted exotic conifer in the world, with over 3.8 million ha in plantations. The Southern Tree Breeding Association (STBA) does most of the breeding for radiata pine in Australia.

Most radiata pine resources in Australia are used for producing structural sawn timber. Wood stiffness, or modulus of elasticity (MOE), is the most important property for structural sawn timber. Both wood density and microfibril angle (MFA) determine the MOE, but MFA is believed to be more important $[5,42]$. Mature wood has more desirable characteristics for structural timber such as high wood density, low MFA and high stiffness [43]. Therefore, it is essential to determine age-age genetic correlations and early selection efficiencies for MOE, and associated traits density and MFA, for breeding programs aimed at structural wood production.
Table I. Site characteristics, experimental design of Rennick and Flynn sites.

\begin{tabular}{lcc}
\hline Site & Flynn & Rennick \\
\hline Latitude & $38^{\circ} 12^{\prime}$ & $37^{\circ} 40^{\prime}$ \\
Longitude & $146^{\circ} 40^{\prime}$ & $140^{\circ} 54^{\prime}$ \\
Elevation $(\mathrm{m})$ & 100 & 70 \\
Rainfall $(\mathrm{mm})$ & 760 & 710 \\
Soil & Sandy loam & Sandy \\
Thinning & None & 3 times $(84,91,97)$ \\
Planting & 1969 & 1969 \\
Year of Harvest & 2000 & 2002 \\
Age & 31 & 33 \\
Family & $36(6$ controls $)$ & $32(2$ controls $)$ \\
Replication & 9 & 5 \\
Tree per plot & 6 & 6 \\
Plot shape & 2 row by 3 column & Single row \\
DBH (mm) & 260 & 443 \\
\hline
\end{tabular}

The aim of this paper was to estimate age-age genetic correlations for wood density, MFA, MOE, and the efficiency of early selection for rotation-aged radiata pine in Australia's breeding population.

\section{MATERIALS AND METHODS}

\subsection{Study material}

Two mature genetic trials planted in 1969 with 30 open-pollinated families were sampled for this study. Seeds of the 30 families were collected in 1968 from the Tallaganda seed orchard in New South Wales [3,31]. The Flynn site was planted with 9 replications and Rennick with 6 replications. Wood disks, billets and bark-to-barkthrough-pith strips at breast height were taken after all trees were felled at Flynn site in 2000 and at Rennick in 2002. Detailed site characteristics are listed in Table I. Rennick site was thinned three times in 1984, 1991, and 1997. All thinnings were from below (smaller stems removed) but with distribution for site occupancy considered. Ninety trees in 30 families from three replications in Rennick were randomly selected for sampling. The Flynn sites were not thinned. As a result, competition was severe and some trees died or stopped growing due to suppression. Therefore, only 90 non-suppressed trees (dominant, codominant and crown exposed) from three replications (one from each plot) were selected for sampling. To study age patterns of heritability and age-age correlations, a total 360 strips, 180 for each of two sites, representing 6 samples for each of 30 families, were taken for SilviScan ${ }^{\circledR}$ measurement of ring width, density, MFA, and MOE $[15,16]$.

Wood density from SilviScan was measured using dry volume and weight at about $7 \%$ relative humidity under about $20{ }^{\circ} \mathrm{C}$ in contrast with green volume (100\% relative humidity) and oven-dry weight (bone dry) used in WinDENDRO X-ray densitometry. Therefore the wood density from SilviScan was higher than using gravimetric density in the paper of $\mathrm{Li}$ and $\mathrm{Wu}[29]$.

SilviScan ${ }^{\circledR}$ predicted dynamic MOE was derived from measured MFA and density according to method described in Evans and Illic [16]. These data were analysed to examine: (1) age trend of ring width, wood density, MFA and dynamic MOE at breast height; 
(2) age trend of heritability of these traits; (3) age-age genetic correlations of these traits; and 4, early selection efficiency.

\subsection{Statistical analyses}

Three thinnings had affected both growth and wood quality traits at Rennick and consequent interactions created some difficulty for the joint analyses of two sites and interpretation of results. Therefore, statistical analyses were conducted based on individual sites. Two samples from each tree were averaged to represent the value of the tree and analyses were conducted based on individual tree models. Preliminary analyses indicated replication by family interactions were not significant for most ages (years) for either growth or wood quality traits while family effect were significant for most ages after age 3. Therefore, all statistical analyses were based on individual tree model as

$$
Y_{i j l}=\mu+R_{i}+F_{j}+e_{i j l}
$$

where $Y_{i j l}$ is the observation of the $l_{t h}$ tree from the $j_{t h}$ family in $i_{t h}$ replication, $\mu$ is the overall mean, both $R_{i}$ (replication) and $F_{j}$ (family) were treated as random effect.

Only results for cumulative growth (DBH -diameter at breast height under bark) and area-weighted (average values for a disk at various ages derived by cumulative ring values weighted by ring area) density, MFA, and MOE are presented here. Covariance components between ages of same traits were calculated according to expectation of cross-products for two variables. SAS Proc GLM [38] was used to obtain sums-of-squares and cross-products matrices. The openpollinated offspring of families were assumed to have a half-sib relationship, and additive genetic variance for each trait was calculated as 4 times the family variance [18]. Narrow-sense heritability $\left(h_{i}^{2}\right)$ was computed for each year at each site assuming half-sib family structure as

$$
h^{2}=\frac{4 \times \sigma_{\text {family }}^{2}}{\sigma_{\text {family }}^{2}+\sigma_{e}^{2}}
$$

where $\sigma_{\text {family }}^{2}$ is the family variance, and $\sigma_{e}^{2}$ is the residual variance. Early- to rotation-age genetic correlations were calculated as:

$$
r=\frac{\operatorname{cov}_{\text {family }_{E R}}}{\sigma_{\text {familyE }_{E}} \times \sigma_{\text {family }_{R}}}
$$

where $\operatorname{cov}_{\text {familyER }}$ is the family covariance among early age $E$ and rotation age $R, \sigma_{\text {family } E}^{2}$ and $\sigma_{\text {family } R}^{2}$ are family variances for early age $E$ and rotation age $R$, respectively. The efficiency of early selection relative to harvest age per generation is calculated as

$$
E f_{\text {gen }}=\frac{i_{E} r_{A} h_{E}}{i_{R} h_{R}}
$$

where $i_{E}$ and $i_{R}$ are the selection intensity at the early and rotation age, respectively, $h_{E}$ and $h_{R}$ are the square root of the heritability at the early and rotation ages, respectively, and $r_{A}$ is the additive genetic correlation between the early and rotation ages. The same selection intensity for the early and rotation ages was used in this calculation.

\section{RESULTS}

\subsection{Analysis of variances}

At Flynn, after age 4, family had significant effect at most ages at the $5 \%$ probability level for both wood density and

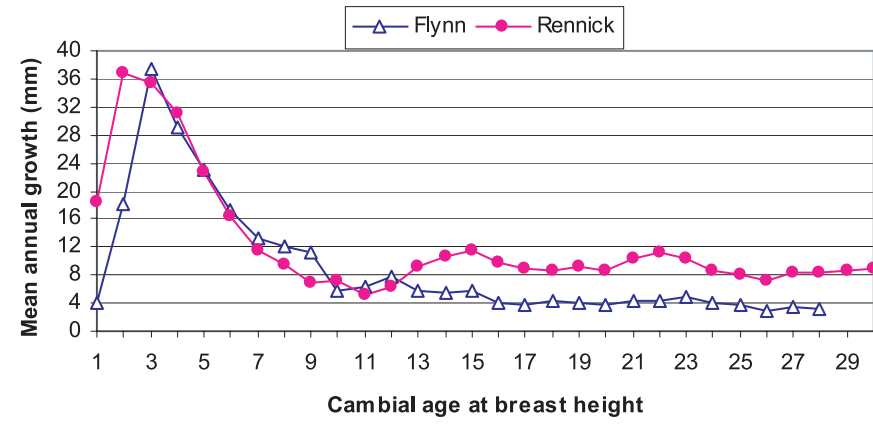

Figure 1. Trend of annual ring growth from cambial age 1 to 28 (30) at breast height for Flynn and Rennick site.

MFA (Tab. II). However, for MOE, family effect was significant only at $10 \%$ probability level for ages between 8 and 15 years and family effect was not significant for DBH. Similarly at Rennick, family had significant effect at most ages at the 5\% probability level for both wood density and MFA after age 5. Family effect was only significant between age 6 to 28 years at $10 \%$ probability level for MOE at Rennick site, but significant for three years (age 18, 19 and 20 years) at 5\% level, and family effect was significant after five years for DBH. The significance at higher probability level for MOE may reflect the small size of samples in this study. Therefore the patterns rather than individual values may be more valuable in this study.

\subsection{Radial trend for growth and wood quality traits}

The age trends for annual ring width (growth), wood density, MFA and MOE from cambial ages 1 to 28 (Flynn) and to 30 (Rennick) based on individual growth rings are shown in Figures 1-4. Annual radial growth was the greatest at early ages (maximum growth around age 3 from pith) and declined rapidly to stabilise after ages 10 and 11 (Fig. 1). Annual radial growth at Rennick (about $8 \mathrm{~mm}$ ) was higher, almost double that at Flynn after age 13 (about $4 \mathrm{~mm}$ ). Rennick had better site quality with more fertile soil. Three thinnings at Rennick also increased ring growth initially. Thinning at cambial age 13 (1984), 20 (1991) and 26 (1997) had lifted radial growth by between $2-5 \mathrm{~mm}$. Thinning at young ages increased ring growth more than thinning at later-ages, but the increase of growth only lasted about two or three years. For example, thinnings at ages 13 and 20 increased ring width about $5 \mathrm{~mm}$ relative to $2 \mathrm{~mm}$ from thinning at age 26 .

Wood density was the lowest near the pith (about $400 \mathrm{~kg} / \mathrm{m}^{3}$ ) and increased steadily to about $610 \mathrm{~kg} / \mathrm{m}^{3}$ ) at age 15 for the Flynn site (Fig. 3). The Rennick site had a similar pattern for density, but had slightly higher density between ages 5 to 13. Rennick also reached a stable ring density earlier (about age 11). Three thinnings reduced wood density slightly for about one or two years.

Microfibril angle was highest near the pith (around $35^{\circ} \mathrm{C}$ ) for both sites and declined to about $10-13^{\circ}$ between ages 9 and 12 . Rennick had slightly lower microfibril angle at early ages, but slightly higher angle at later ages. It seems thinnings 
Table II. Significance level of family effect for DBH growth, wood density, MFA and MOE in Rennick and Flynn sites.

\begin{tabular}{|c|c|c|c|c|c|c|c|c|}
\hline \multirow[t]{2}{*}{ Age } & \multicolumn{4}{|c|}{ Flyynn } & \multicolumn{4}{|c|}{ Rennick } \\
\hline & DBH & Density & MfA & $\mathrm{MoE}$ & DBH & Density & MfA & $\mathrm{MoE}$ \\
\hline$\overline{1}$ & 0.837 & 0.683 & 0.316 & 0.553 & 0.603 & 0.836 & 0.558 & 0.507 \\
\hline 2 & 0.664 & 0.480 & 0.344 & 0.388 & 0.418 & 0.259 & 0.131 & 0.447 \\
\hline 3 & 0.654 & 0.430 & 0.366 & 0.298 & 0.366 & 0.526 & 0.084 & 0.173 \\
\hline 4 & 0.846 & 0.153 & 0.175 & 0.254 & 0.670 & 0.406 & 0.072 & 0.126 \\
\hline 5 & 0.745 & 0.012 & 0.046 & 0.187 & 0.186 & 0.154 & 0.106 & 0.179 \\
\hline 6 & 0.584 & 0.017 & 0.040 & 0.192 & 0.042 & 0.026 & 0.101 & 0.108 \\
\hline 7 & 0.407 & 0.044 & 0.041 & 0.191 & 0.038 & 0.024 & 0.054 & 0.106 \\
\hline 8 & 0.418 & 0.023 & 0.024 & 0.095 & 0.030 & 0.038 & 0.030 & 0.075 \\
\hline 9 & 0.464 & 0.027 & 0.019 & 0.067 & 0.027 & 0.034 & 0.014 & 0.093 \\
\hline 10 & 0.467 & 0.041 & 0.017 & 0.084 & 0.021 & 0.026 & 0.008 & 0.090 \\
\hline 11 & 0.506 & 0.056 & 0.014 & 0.085 & 0.020 & 0.020 & 0.006 & 0.078 \\
\hline 12 & 0.497 & 0.060 & 0.010 & 0.073 & 0.018 & 0.027 & 0.005 & 0.065 \\
\hline 13 & 0.405 & 0.077 & 0.012 & 0.100 & 0.018 & 0.048 & 0.004 & 0.065 \\
\hline 14 & 0.360 & 0.049 & 0.007 & 0.089 & 0.016 & 0.044 & 0.004 & 0.058 \\
\hline 15 & 0.327 & 0.045 & 0.008 & 0.091 & 0.014 & 0.038 & 0.005 & 0.061 \\
\hline 16 & 0.256 & 0.044 & 0.009 & 0.100 & 0.010 & 0.040 & 0.006 & 0.058 \\
\hline 17 & 0.227 & 0.050 & 0.010 & 0.139 & 0.007 & 0.036 & 0.005 & 0.057 \\
\hline 18 & 0.203 & 0.056 & 0.010 & 0.132 & 0.004 & 0.037 & 0.005 & 0.044 \\
\hline 19 & 0.188 & 0.057 & 0.009 & 0.130 & 0.002 & 0.041 & 0.004 & 0.045 \\
\hline 20 & 0.194 & 0.061 & 0.009 & 0.129 & 0.002 & 0.051 & 0.004 & 0.046 \\
\hline 21 & 0.225 & 0.044 & 0.010 & 0.157 & 0.002 & 0.056 & 0.005 & 0.060 \\
\hline 22 & 0.225 & 0.034 & 0.015 & 0.162 & 0.001 & 0.043 & 0.011 & 0.074 \\
\hline 23 & 0.251 & 0.031 & 0.025 & 0.149 & 0.001 & 0.045 & 0.012 & 0.078 \\
\hline 24 & 0.262 & 0.031 & 0.028 & 0.158 & 0.001 & 0.047 & 0.012 & 0.082 \\
\hline 25 & 0.402 & 0.030 & 0.030 & 0.195 & 0.001 & 0.037 & 0.013 & 0.068 \\
\hline 26 & 0.405 & 0.033 & 0.036 & 0.211 & 0.001 & 0.043 & 0.014 & 0.074 \\
\hline 27 & 0.397 & 0.028 & 0.036 & 0.190 & 0.002 & 0.055 & 0.015 & 0.081 \\
\hline 28 & 0.359 & 0.031 & 0.019 & 0.196 & 0.003 & 0.047 & 0.020 & 0.095 \\
\hline 29 & 0.145 & 0.033 & 0.034 & 0.287 & 0.004 & 0.054 & 0.025 & 0.116 \\
\hline 30 & & & & & 0.006 & 0.052 & 0.031 & 0.135 \\
\hline
\end{tabular}

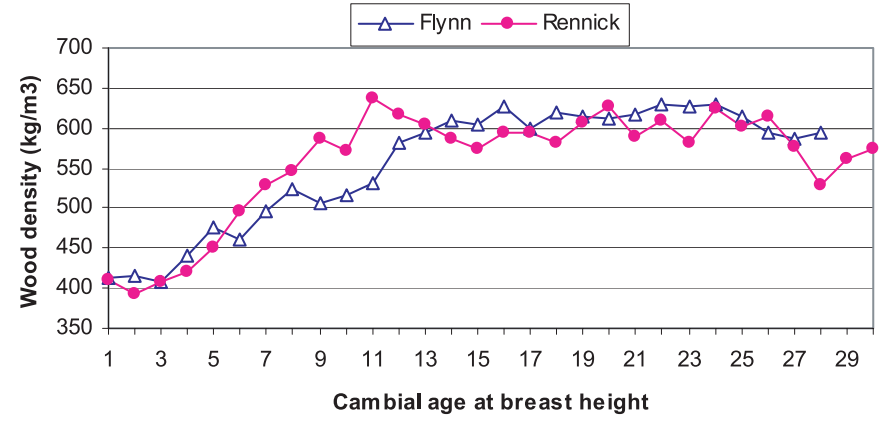

Figure 2. Trend of annual wood density from cambial age 1 to 28 (30) at breast height for Flynn and Rennick site.

had increased microfibril angle slightly for about two years (Fig. 3).

Similar to wood density, MOE increased from about $2.5 \mathrm{GPa}$ near the pith to about $20 \mathrm{GPa}$ at ages 15 or 16 years for Flynn. Rennick had slightly higher MOE at early ages but lower MOE than for Flynn after age 13 years. Thinning at Rennick may have reduced MOE by about $4-8 \%$ for about two years (Fig. 4).

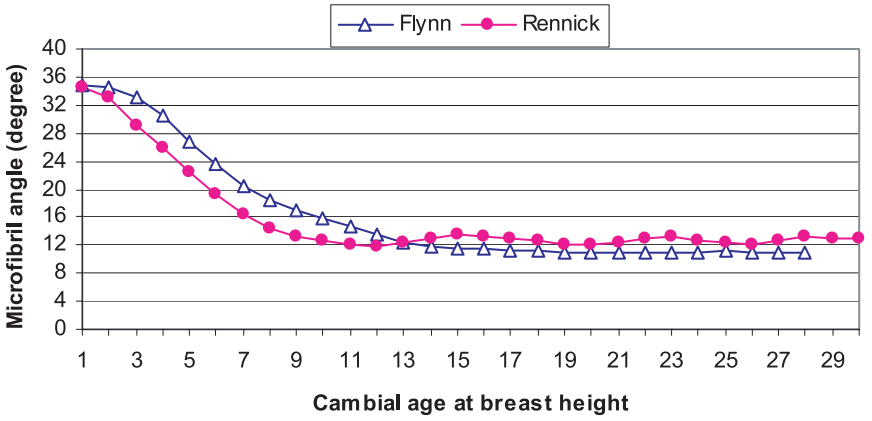

Figure 3. Trend of annual microfibril angle from cambial age 1 to 28 (30) at breast height for Flynn and Rennick site.

\subsection{Trend of heritability}

Heritability for DBH (accumulated ring width) at Flynn was less than 0.2 before age 14, and between about 0.2 and 0.4 after age 14 (Fig. 5). Heritability for DBH at Rennick was higher after age 4 and reached 0.4 at age 6 , and varied between 0.4 and 0.7 after age 6 .

Heritability for area-weighted density was high for both the Flynn and Rennick sites. At Flynn, heritability increased 


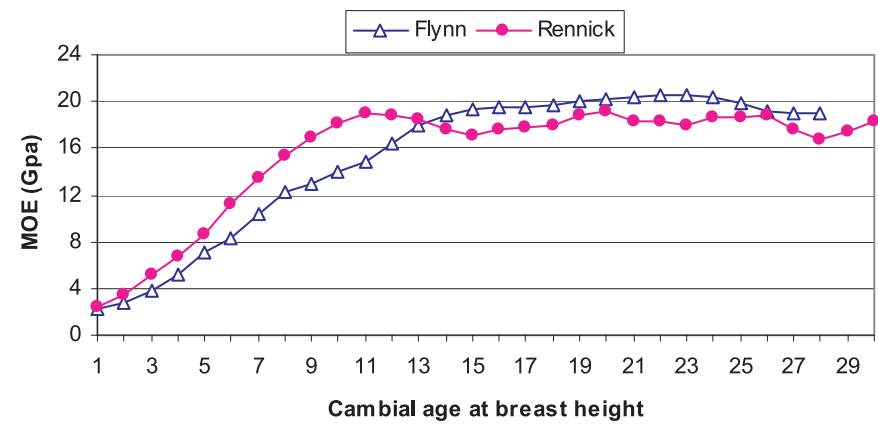

Figure 4. Trend of annual modulus of elasticity (MOE) from cambial age 1 to 28 (30) at breast height for Flynn and Rennick site.

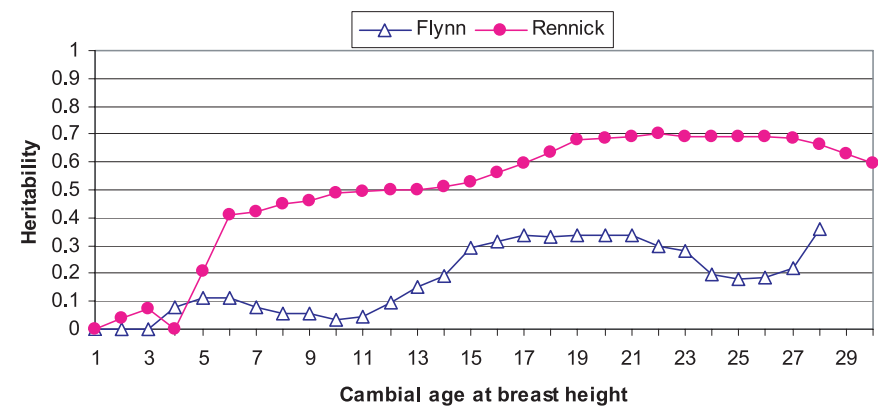

Figure 5. Heritability trend for diameter under bark from cambial age 1 to 28 (30) at breast height for Flynn (s.e. 0.37-0.44) and Rennick site (s.e. $0.36-0.44)$.

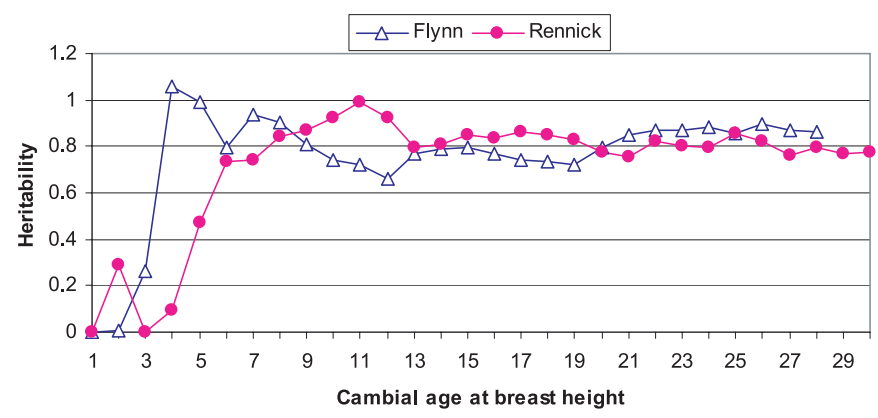

Figure 6. Heriability trend for area-weighted wood density from cambial age 1 to 28 (30) at breast height for Flynn (s.e. 0.42-0.48) and Rennick site (s.e. 0.39-0.45).

quickly from age 1 to 4 . After age 4, heritability varied around 0.8 for most years (Fig. 6). Similarly, heritability of areaweighted density at Rennick reached about 0.8 at age 6 , with small fluctuations after that age.

Area-weighted microfibril angle also had a high heritability. Heritability at Flynn reached 0.8 at age 4, was above one (with sampling error between 0.28 and 0.40 ) after age 10 , and was between 0.8 and 1.0 between age 21 and 28 (Fig. 7). At Rennick, heritability increased to 0.6 at age 7 and then remained around 0.8 , but with an apparent drop after age 26 .

In general, heritability for MOE was higher than for $\mathrm{DBH}$, but lower than for area-weighted density and microfibril an-

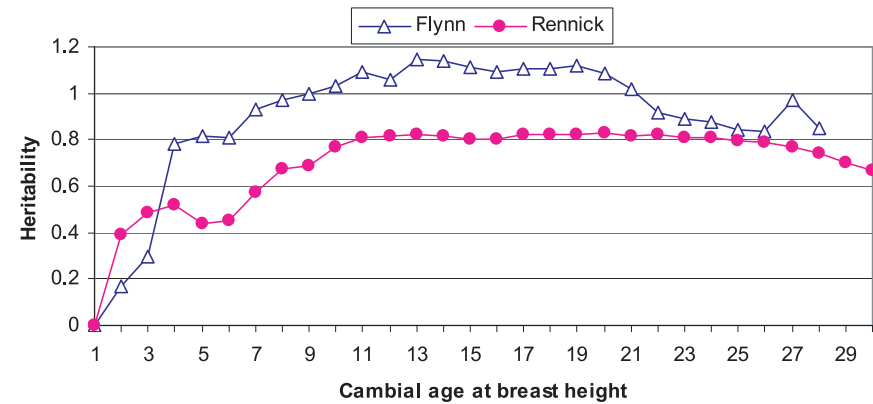

Figure 7. Heriability trend for area-weighted microfibril from cambial age 1 to 28 (30) at breast height for Flynn (s.e. 0.41-0.49) and Rennick site (s.e. 0.40-0.44).

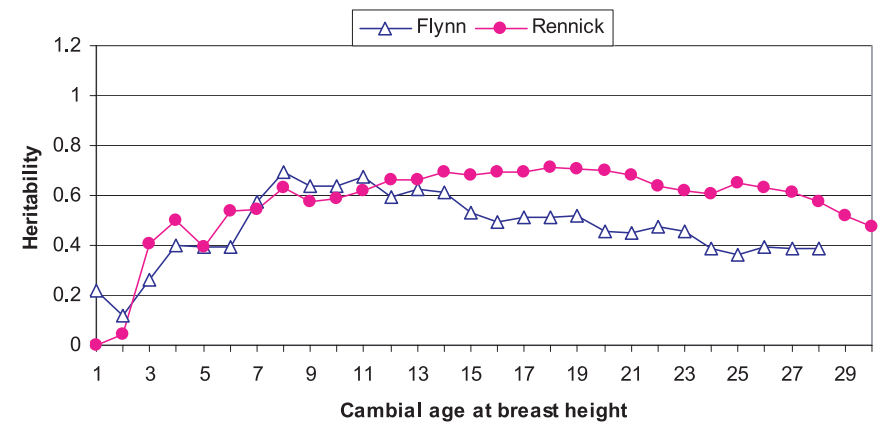

Figure 8. Heriability trend for area-weighted modulus of elasticity from cambial age 1 to 28 (30) at breast height for Flynn (s.e. 0.38$0.46)$ and Rennick site (s.e. $0.37-0.44)$.

gle. Heritability of MOE was between 0.4 and 0.6 for most ages at Flynn after age 4 (Fig. 8) and was between 0.4 and 0.7 after age 2 at Rennick. There was relative large standard error for these heritability estimates. Most of the estimated standard errors were above 0.4 with range from 0.36 to 0.49 .

\subsection{Genetic correlation between harvest and earlier ages}

The additive genetic correlation between harvest age and very early age (ages $1-6)$ was very low $(<0.2)$ for DBH at Flynn and increased from 0.2 to 0.8 between ages 7 to 12 (Fig. 9). The Rennick site had higher additive genetic correlations and the correlation was about 0.5 at age 5 and increased to about one at age 13 .

The genetic correlations between harvest age and earlier ages were higher for density, MFA and MOE. The genetic correlation for wood density reached above 0.6 at age 3 at Flynn (Fig. 10) while Rennick reached 0.6 two years later. The ageage genetic correlation for wood density at Flynn was higher than at Rennick before age 18. The age-age genetic correlation for MFA was the highest at early ages among the three wood quality traits. Correlation reached 0.6 and above at age 2 (Fig. 11). Similar as for wood density, the age-age genetic 


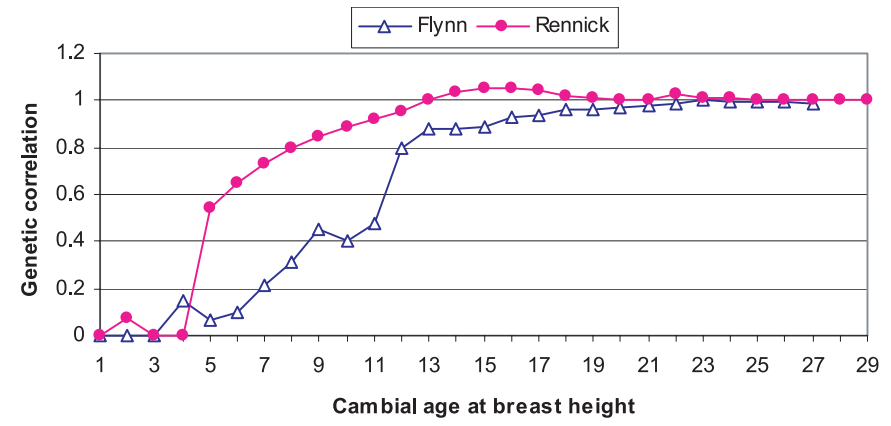

Figure 9. Genetic correlation between harvest age and earlier ages for diameter under bark for Flynn and Rennick site.

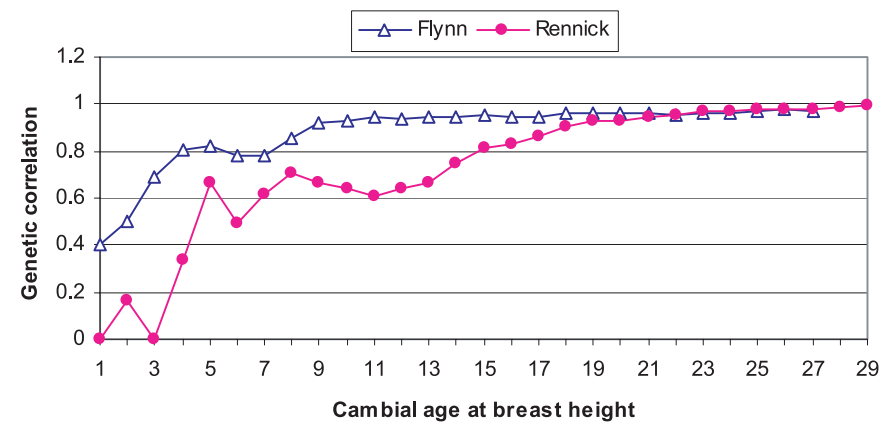

Figure 10. Genetic correlation between harvest age and earlier ages for wood density for Flynn and Rennick site.

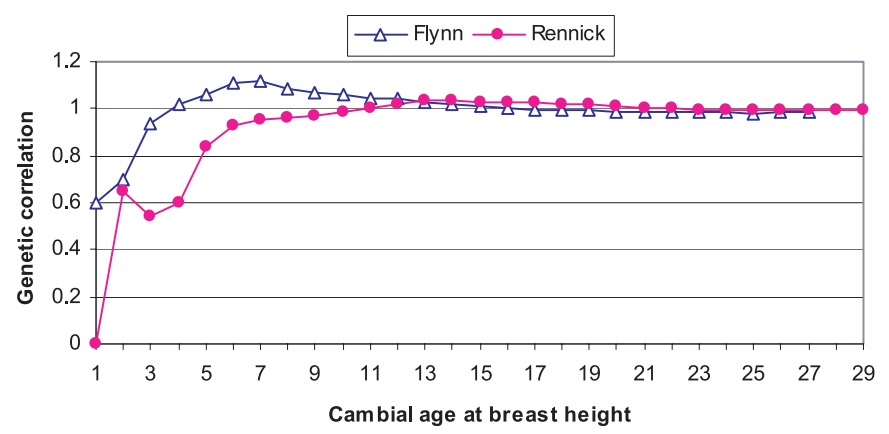

Figure 11. Genetic correlation between harvest age and earlier ages for microfibril angle for Flynn and Rennick site.

correlations for MOE were higher at Flynn at early ages and reached above 0.8 at age 4 (Fig. 12).

\subsection{Efficiency of early selection relative to selection at harvest age}

Efficiency of early selection at Rennick for DBH was much higher than at Flynn, particularly at early ages (ages 4 to 15, Fig. 13). This mainly reflected the higher heritability and the age-age genetic correlation at Rennick. Early selection at age 16 had the same gain as selection at harvest at Rennick.

Efficiency for early selection was higher for wood density relative to growth (Fig. 14). Efficiency for wood density reached $0.8(80 \%)$ at age 4 at Flynn while the same efficiency

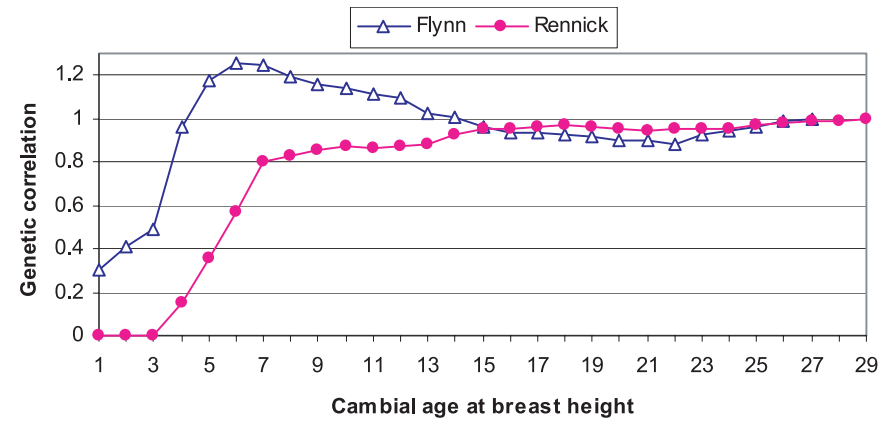

Figure 12. Genetic correlation between harvest age and earlier ages for modulus of elasticity for Flynn and Rennick site.

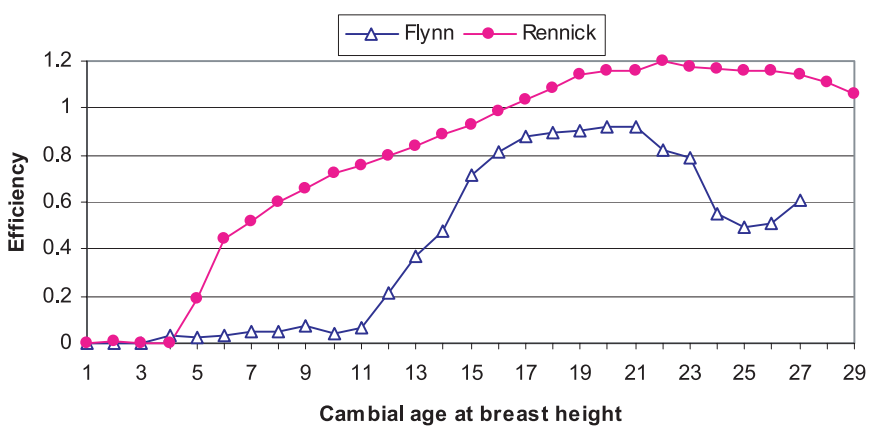

Figure 13. Efficiency of early selection for harvest age diameter under bark for Flynn and Rennick site.

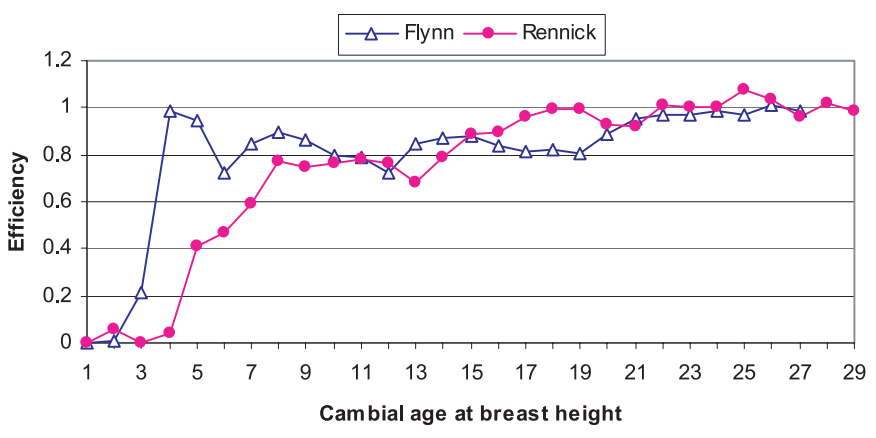

Figure 14. Efficiency of early selection for harvest age area-weighted wood density for Flynn and Rennick site.

was achieved at age 8 at Rennick. Early selection efficiency was even higher for MFA (Fig. 15). Early selection at age 4 at Flynn and age 8 at Rennick was almost as efficient as selection conducted at harvest age. Similar to MFA, early selection for MOE at age 4 at Flynn and age 8 at Rennick was almost as efficient as selection conducted at harvest age (Fig. 16). The selection efficiencies were even higher after these ages for both MFA and MOE.

\section{DISCUSSION AND CONCLUSIONS}

Study of early selection efficiency involves estimation of genetic parameters across ages. To estimate genetic variance and covariance matrices across ages, a critical issue is how to 


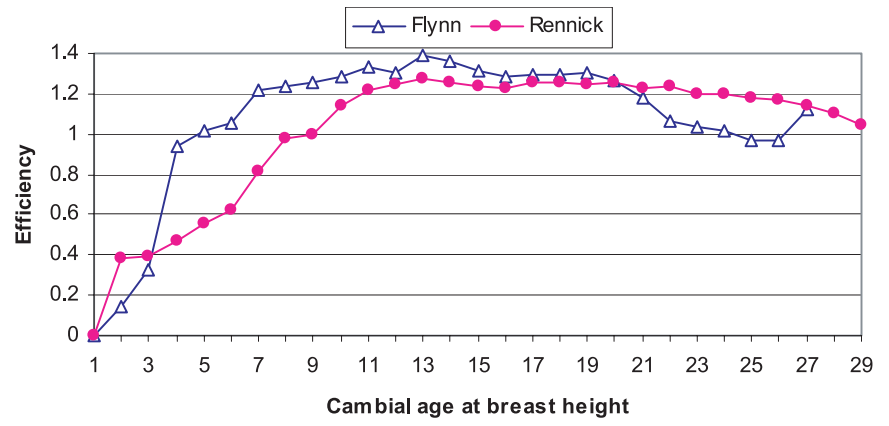

Figure 15. Efficiency of early selection for harvest age area-weighted microfibril angle for Flynn and Rennick site.

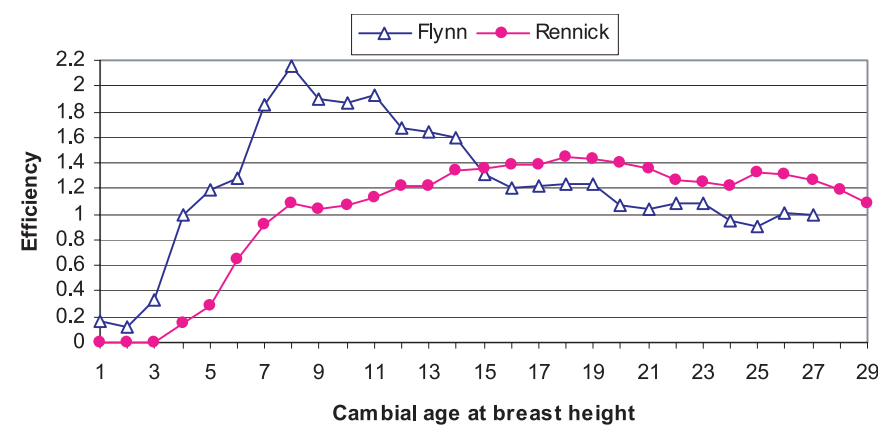

Figure 16. Efficiency of early selection for harvest age area-weighted modulus of elasticity for Flynn and Rennick site.

best sample trees for estimating genetic parameters in an unbiased manner. Sampling of trees at different ages with minimal bias is a significant challenge for age-age genetic correlation study. Genetic parameters estimated at early ages were less biased since trials were usually well maintained with a minimum of competition among trees and low mortality. As trees mature, inter-tree competition intensifies, and some trees may die while others may be suppressed by bigger neighbouring trees. Thus, trees sampled at later ages may not be the same trees as those used for early estimates. To estimate genetic correlations between early and later ages, only trees surviving to later ages, or that are not severely suppressed may be used. To avoid such sampling bias, only non-suppressed trees were sampled for wood quality studies. However, non-suppressed trees are usually dominant or partially dominant trees. Therefore, such sampling procedure may also create a bias by possibly reducing the within-family variance, and inflating estimates of heritability.

We observed that site affected all wood quality characteristics and growth in this study. This may not be surprising considering that site and genetic effects were observed having the largest influence on radiata pine wood quality traits [4,8,9,34]. An interesting observation is that Rennick site not only had faster growth rate, but also higher wood density, lower MFA and higher MOE at early ages (before age 13). The relationship between wood quality traits and growth has been widely studied, and it is sometimes controversial, especially the relationship between wood density and growth [52]. The liter- ature mostly reports inverse but weak relationships [11, 14], while others found no significant relationships at al. [52]. Positive relationship between density and growth is also possible if the larger rings were companied with the increased proportion of latewood $[13,45]$. At Rennick, many disks showed higher proportion of latewood in the early rings before the thinning. Rennick site also had higher growth after age 13, but generally slightly lower density, higher MFA, and lower MOE. The three thinnings may have complicated the patterns.

Thinning had increased ring width and MFA, but reduced wood density and MOE at Rennick. Such thinning effects were sometimes observed in radiata pine $[7,36,40]$ and other conifer species [41,52]. By comparing heritabilities for two sites, it seems that the commercial thinning seemed to inflate heritability estimates on growth $(\mathrm{DBH})$, but had less impact on heritability of wood quality traits.

In general, heritability increased from zero at age 1 to a stable value at age 4 and 5 for all four traits (DBH, weighted density, MFA and MOE). Heritability was the highest for areaweighted density and MFA across ages, lowest for DBH and intermediate for MOE. High heritability for density, MFA, and MOE indicates that selection would be very effective for these wood quality traits, particularly 4 or 5 years after planting. These heritabilities were slightly higher than some published results for radiata pine. Heritability for density averaged 0.69 (with weighted average 0.71 ) from a literature survey of 39 published genetic studies of radiata pine growth and wood quality genetic studies [49], while the mean heritability was 0.80 for two sites from age 4 . Heritability for MFA was 0.60 and 0.69 , respectively from two studies $[12,39]$ in comparison with the mean heritability of 0.85 from age 4 in this study. Estimated heritability for MOE from the two previous studies was 0.89 and 0.42 , respectively $[33,39]$. Our average estimate in this study was 0.56 from age 4 .

The heritability estimates in this sample was higher than previous estimates using same trial (Flynn), but different samples and different method of wood density assessment. The difference may be contributed by different measures of density and calibration methods used. In this study, SilviScan profiling of wood density from pith to bark was used for genetic analyses. In SilviScan, density profile within a sample was calibrated using the pre-measured density of the sample. In a previous report [29], WinDENDRO X-ray densitometry was used to profile density from pith to bark. In WinDENDRO, a film calibration value was used to calibrate each Xray plate which contains several samples. In doing so, variation among samples and within profile of a sample may be reduced. This, in combination of the joint two-site analyses, may underestimated heritability for wood density in the previous report. Considering large standard error in estimating heritability, there seemed no significant difference between these estimates. The main interests of these studies were to examine efficiency of early selection, the absolute values may not be as important as relative values for two heritability (early and late ages) of the same experiment. Therefore, the different estimates due to different methods may have minimum effect on estimating early selection efficiency. 
Early to rotation age-age genetic correlation were very high in this study, particularly for wood quality traits. Age-age correlation for $\mathrm{DBH}$ was found to be higher for Rennick than for Flynn. The highest age-age genetic correlation among the three wood quality traits was observed in MFA. For MFA, genetic correlation reached one at ages 4 and 11 for Flynn and Rennick, respectively. It was observed that several genetic correlations were above one. Genetic correlations are subject to large errors, and, given the small population size (30 families and six samples per family) at each site, a large error may be associated with these estimates. When individual values are subject to fluctuations, a trend as listed in this study may be more valuable then individual estimates.

Early selection was observed to be more efficient in wood quality traits than in $\mathrm{DBH}$, similar to the finding by $\mathrm{Li}$ and $\mathrm{Wu}$ [29]. This is not surprising giving higher heritability of wood quality traits and closer genetic correlation. Comparisons with other studies were difficult since the mature ages used are varied greatly, and gains were computed based on gain per generation in some publications or gain per year in other publications. Due to small sample size, particularly for DBH, early selection efficiency for DBH should be referred with caution. Early selection efficiency for DBH reached a plateau at age 16 and 17 for rotation age 30 at Rennick, was later than the age 6.5 for age 16 observed by Cotterill and Dean [6], and age 10 for age 14 for cross-sectional area [32], or ages 8 to 10 for DBH based on gain per year [29]. King and Burdon [24] found a maximum efficiency at ages 7-8 years for rotations of 25-30 years for stem volume in New Zealand.

For wood density, early selection at ages 4 to 5 years would be 40 to $80 \%$ effective relative to rotation age. After age 7 , there is little gain for selection at later ages relative to rotation age selection. Effectiveness of early selection for wood density is similar to observations by $\mathrm{Li}$ and $\mathrm{Wu}$ [29] and Kumar and Lee [25] in radiata pine. These optimal early selection ages fall within current wood quality assessment ages (age 5 to 8) for Australian radiata pine breeding program.

At Flynn, MFA and MOE selection at ages 4 or 5 would be similarly efficient as selection at rotation age. For Rennick, it was about 3 years later: selection at ages 7 or 8 would have same efficiency as selection at rotation age. Therefore from this study, early age selection for MFA and MOE could be effective from age 4 to 8 for radiata pine.

The study can be summarised as:

1. Wood density was the lowest near the pith, increased steadily to age 11-15 years, then was relatively stable after these ages.

2. MFA was the highest $\left(35^{\circ}\right)$ near the pith and declined to about $10^{\circ}$ at ages $10-15$ years. MFA changed little at later ages.

3. MOE increased from about $2.5 \mathrm{GPa}$ near the pith to about $20 \mathrm{GPa}$ at ages $11-15$ years. MOE remained relatively unchanged at later ages.

4. Age-age genetic correlations were very high for wood quality traits and DBH. The genetic correlation reached 0.8 after age 7 for most of the traits with the exceptions of DBH. Such high genetic correlation indicates that early selection should be very effective. Selection at age 7-8 has similar effectiveness as selection conducted at rotation age for MFA and MOE and at least $80 \%$ effective for wood density.

5. Thinning of trials increased ring width and MFA, reduced ring wood density and MOE of remaining trees in the first two or three years after thinning. However the effects of thinning at later ages were smaller than in the early thinnings.

Acknowledgements: This study was jointly funded by FWPRDC, STBA, and CSIRO for the breeding objective project PN01.1904. We thank John Owen, David Spencer, Steve Elms, Peter Buxton, Aljoy Abarquez, Brioni Brammall, and Sarah Whitfeld for their assistances in field sampling. Washington Gapare and Geoff Downes reviewed the manuscript.

\section{REFERENCES}

[1] Anonymous, Australian forest and wood product statistics, ABARE, Canberra, 2004.

[2] Bastien J.C.H., Roman-Amat B., Predicting Douglas-fir (Pseudotsuga menziesii Mirb.) Franco) volume at age 15 with early traits, Silvae Genet. 39 (1990) 29-34.

[3] Brown A.G., Experience in management of a radiata pine seed orchard at Tallaganda State Forest, New South Wales, Aust. For. Res. 5, (1971) 15-30.

[4] Burdon R.D., Harris J.M., Wood density in radiata pine clones on four different sites, N.Z. J. For. Sci. 3, (1973) 286-303.

[5] Cave I.D., Walker J.C.W., Stiffness of wood in fast-grown plantation softwoods: the influence of microfibril angle, For. Prod. J. 44 (1994) 43-48.

[6] Cotterill P.P., Dean C.A., Changes in the genetic control of growth of radiata pine to 6-years and efficiencies of early selection, Silvae Genet. 37 (1988) 138-146.

[7] Cown D.J., McConchie D.L., Effects of thinning and fertilizer application on wood properties of Pinus radiata, N.Z. J. For. Sci. 11 (1981) 79-91.

[8] Cown D.J., McConchie D.L., Young G.D., Radiata pine: wood properties survey, FRI Bulletin No. 50, Forest research Institute, Rotorua, New Zealand, 1991, $50 \mathrm{p}$.

[9] Cown D.J., Young G.D., Burdon R.D., Variation in wood characteristics of 20-year-old half-sib families of Pinus radiata, N.Z. J. For. Sci. 22 (1992) 63-76.

[10] Danjon, F., Heritabilities and genetic correlations for estimated growth curve parameters in maritime pine, Theor. Appl. Genet. 89 (1994) 911-921.

[11] DeBell J.D., Tappeiner J.C., Krahmer R.L., Wood density of western hemlock: effect of ring width, Can. J. For. Res. 24 (1994) 638641.

[12] Donaldson L.A., Burdon R.D., Clonal variation and repeatability of microfibril angle in Pinus radiata, N.Z. J. For. Sci. 25 (1995) 164174.

[13] Downes G.M., Wimmer R., Evans R., Understanding wood formation: Gains to commercial forestry through tree ring research, Dendrochronologia 20 (2002) 37-51.

[14] Dutilleul P., Herman M., Avella Shaw T., Growth rate effects on correlations among ring width, wood density, and mean tracheid length in Norway spruce (Picea abies), Can. J. For. Res. 28 (1998) 56-68.

[15] Evans R., Hughes M.A., Menz D.J., Microfibril angle variation by scanning x-ray diffractometry, Appita J. 52 (1999) 363-367. 
[16] Evans R., Ilic J., Rapid prediction of wood stiffness from microfibril angle and density, For. Prod. J. 51 (2001) 53-57

[17] Eriksson G., Jonsson A., Dormling I., Norell L., Stener L.G., Retrospective early tests of Pinus sylvestris L. seedlings grown under five nutrient regimes, For. Sci. 39 (199) 95-117.

[18] Falconer D.S., Mackay T.F.C., Introduction to Quantitative Genetics. Addison Wesley Longman Group Ltd, UK, 4th ed., 1996, $464 \mathrm{p}$.

[19] Gwaze D.P., Bridgwater F.E., Byram T.D., Woolliams J.A., Williams C.G., Predicting age-age genetic correlations in treebreeding programs: a case study of Pinus taeda L., Theor. Appl. Genet. 100 (2000) 199-206.

[20] Hannrup B., Ekberg I., Age-age correlations for tracheid length and wood density in Pinus sylvestris, Can. J. For. Res. 28 (1998) 13731379.

[21] Hodge G.R., White T.L., Genetic parameter estimates for growth traits at different ages in slash pine and some implications for breeding, Silvae Genet. 41 (1992) 252-261.

[22] Hylen G., Age trends in genetic parameters of wood density in young Norway spruce, Can. J. For. Res. 29 (1999) 135-143.

[23] Johnson G.R., Sniezko R.A., Mandel N.L., Age trends in Douglasfir genetic parameters and implications for optimum selection age, Silvae Genet. 46 (1997) 349-358.

[24] King J.N., Burdon R.D., Time trends in inheritance and projected efficiencies of early selection in a large 17-year-old progeny test of Pinus radiata, Can. J. For. Res. 21 (1991) 1200-1207.

[25] Kumar S., Lee J., Age-age correlations and early selection for endof-rotation wood density in radiata pine, For. Gen. 9 (2002) 323330.

[26] Lambeth C.C., Juvenile-mature correlations in Pinaceae and implications for early selection, For. Sci. 26 (1983) 571-580.

[27] Lambeth C.C., van Buijtenen J.P., Duke S.D., McCullough R.B., Early selection is effective in 20-year-old genetic tests of loblolly pine, Silvae Genet. 32 (1983) 210-215.

[28] Li B., Mckeand S.E., Allen H.L., Seedling shoot growth of loblolly pine families under two nitrogen levels as related to 12-year height Can. J. For. Res. 21 (1991) 842-847.

[29] Li L., Wu H.X., Efficiency of early selection for rotation-aged growth and wood density traits in Pinus radiata, Can. J. For. Res. 35 (2005) 1-11.

[30] Magnussen S., Growth differentiation in white spruce crop tree progenies, Silvae Genet. 42 (1993) 258-266.

[31] Matheson A.C., Raymond C.A., The impact of genotype $\times$ environment interactions on Australian Pinus radiata breeding programs, Aust. For. Res. 14 (1984) 11-25.

[32] Matheson A.C., Spencer D.J., Magnussen D., Optimum age for selection in Pinus radiata basal area under bark for age:age correlations, Silvae Genet. 43 (1994) 352-357.

[33] Matheson A.C., Yang J.L., Spencer D.J., Breeding radiata pine for improvement of sawn product value, CTIA/IUFRO Wood quality Workshop IV. 1997, pp. 19-26.

[34] McKinley R., Klitscher K., Factors affecting wood density of radiata pine - an update, FRI Bulletin No. 201, Forest research Institute, Rotorua, New Zealand, 1995, pp. 46-53.
[35] Nyakuengama J.G., Matheson A.C., Evans R., Spencer D., Vinden P., Time trends in the genetic control of wood microstructure traits in Pinus radiata, Appita 50 (2002) 486-494.

[36] Nyakuengama J.G., Downes G.M., Ng J., Growth and density responses to later-age fertilizer application in Pinus radiata D. Don, IAWA J. 23 (2002) 431-448.

[37] Pharis R.P., Yeh F.C., Dancik B.P., Superior growth potential in trees: what is its basis, and can it be tested for at an early age? Can J. For. Res. 21 (1991) 368-374.

[38] SAS Institute Inc., SAS/STAT ${ }^{\circledR}$ software: changes and enhancements through release 6.12. SAS Institute Inc., Cary, N.C., 1997.

[39] Shelbourne C.J.A., Genetics of adding value to the end-products of radiata pine. IUFRO ' 97 Genetics of radiata pine, FRI bulletin No. 203, 1997, pp. 129-141.

[40] Siemon G.R., Effects of thinning on crown structure, stem form and wood density of radiata pine. Ph.D. thesis, Australian National University, Australia, 1973

[41] Tasissa G., Burkhart H.E., Modelling thinning effects on ring specific gravity of loblolly pine (Pinus taeda), For. Sci. 44 (1998) 212 223.

[42] Walker J.C.F., Butterfield B.G., The importance of microfibril angle for the processing industries, N.Z. Forestry 40 (1995) 34-40.

[43] Walker J.F.C., Nakada R., Understanding corewood in some softwoods: a selective review on stiffness and acoustics, Int. For. Rev. 1 (1999) 251-259.

[44] Williams C.G., The influence of shoot ontogeny on juvenile-mature correlation in Loblolly pine, For. Sci. 33 (1987) 441-422.

[45] Wimmer R., Downes G.M., Temporal variation of the ring width wood density relationship in spruce stands affected by air pollution, IAWA J. 24 (2003) 53-61.

[46] Williams C.G., Accelerated short-term genetic testing for loblolly pine families, Can. J. For. Res. 18 (1988) 1085-1089.

[47] Wood M., Stephens N., Allison B., Howell C., Plantations of Australia - A report from the National Plantation Inventory and the National Farm Forest Inventory, National Forest Inventory, Bureau of Rural Science, Canberra, 2001.

[48] Wu H.X., Study of early selection in tree breeding: 2. Advantage of early selection through shortening of breeding cycle, Silvae Genet. 79-83, 1999.

[49] Wu H.X., Yang J., McRae T.A., Li L., Powell M.B., Genetic relationship between breeding objective and early selection criterion traits in Australia radiata pine population, CSIRO CFFP Technical Report 1402 and STBA Technical Report TR04-01, 2004, 51 p.

[50] Ying C.C., Morgenstern E.K., Correlations of height growth and heritabilities at different ages in white spruce. Silvae Genet. 28 (1979) 181-185.

[51] Zas R., Merlo E., Fernandez-Lopez L., Juvenile-mature genetic correlations in Pinus pinaster under different nutrient $\times$ water regimes, Silvae Genet. 53 (2004) 124-129.

[52] Zobel B.J., van Buijtenen J.P., Wood variation: its causes and control, Springer Series in Wood Science, Springer-Verlag, Berlin, $1989,363 \mathrm{p}$ 